\author{
전향력이 태풍 발생 및 이동에 미치는 영향을 \\ 이해할 수 있는 실험 방법 개발 \\ 위지은 ${ }^{1} \cdot$ 장승환 $^{1,2, *} \cdot$ 문병권 $^{1}$ \\ ${ }^{1}$ 전북대학교 과학교육학부/과학교육연구소, 561-756, 전라북도 전주시 덕진구 백제대로 567 \\ ${ }^{2}$ 우석고등학교, 561-320, 전라북도 전주시 덕진구 쪽구름 2길 22
}

\title{
Development of an Experimental Method for Understanding the Effects of the Coriolis Force on the Typhoon Genesis and its Movement
}

\author{
Jieun Wie ${ }^{1}$, Swunghwan Jang ${ }^{1,2, *}$, and Byungkwon Moon ${ }^{1}$ \\ 'Devision of Science Education/Institute of Science Education, Chonbuk National University, \\ Jeonbuk 561-756, Korea \\ ${ }^{2}$ Woosuk High School, Jeonbuk 561-320, Korea
}

\begin{abstract}
A simple experimental method was developed to help students understand the effect of the Coriolis force on typhoon genesis and movement. It consists of rotating tanks with and without a sloping bottom, and a small stirrer to produce cyclonic typhoon-like vortices by locally stirring the water. Vortices were able to last for more than 3 minutes without dissipation in the rotating tank. However, vortices were hardly maintained without rotation, and would rather disappear as soon as the stirrer stopped mixing. Since the dynamical properties of the rotating water are similar to those of the atmosphere influenced by the Coriolis force, the experiments show that the Coriolis force is indispensable to the typhoon genesis. When the tank had both the sloping bottom and rotation, vortices would move in a particular direction. Considering the topographical beta effect, this result indicates that typhoons are drifted not only by the steering wind but also by the meridional gradient of the Coriolis force. The methodology developed in this study, would be useful for both students and teachers to better the relationship between the Coriolis force and the typhoon genesis.
\end{abstract}

Keywords: rotating disk, vortex, Coriolis force, beta effect, typhoon

요 약: 태풍 발생과 이동에 미치는 전향력의 영향을 살펴보는데 활용할 수 있는 실험 방법을 개발하였다. 실험 장치는 회전원판, 수조, 그리고 태풍과 유사한 모양의 소용돌이를 생성시키기 위한 발생기 등으로 구성되었다. 회전하는 원판에 놓인 수조에서 생성된 소용돌이는 그 형태가 수 분 동안 유지되었다. 반면에 회전이 없을 때는 소용돌이가 생성되기 어려웠고, 생성되더라도 곧 흩어졌다. 회전 유체의 역학적 특성은 전향력이 작용하는 대기와 유사하므로, 앞의 두 실험 을 통해 태풍이 발생되기 위해서는 반드시 전향력이 필요함을 알 수 있었다. 또한 경사진 바닥을 갖는 수조 속의 소용 돌이는 일정한 방향으로 이동하였다. 지형적 베타 효과를 고려하여, 우리는 바람 효과뿐만 아니라 전향력의 남북방향의 변화가 태풍의 이동에 중요한 영향을 줄 수 있음을 알았다. 이 연구에서 개발한 실험 방법은 학생들이 전향력과 태풍 의 관계를 이해하는데 유용하게 사용될 것으로 기대한다.

주요어: 회전원판, 소용돌이, 전향력, 베타효과, 태풍

\section{서 론}

서태평양에서 매년 발생하는 태풍의 개수는 전 지

*Corresponding author: cats1149@naver.com

Tel: + 82-63-211-0992

Fax: +82-63-212-3117
구에서 발생하는 열대 저기압의 $30 \%$ 를 차지하며, 적 게는 3 개에서 최대 10 개 정도가 동아시아의 중위도 지역에 매년 영향을 주고 있다(최기선과 김태룡, 2011). 우리나라 여름철 강수량은 전체 강수량의 $50 \%$ 를 차지하며 시간이 지날수록 태풍에 의한 강수 량은 증가하고 있다(Cha et al., 2007). 또한 1981년 
이후 한반도에 상륙하는 태풍의 횟수가 급격하게 증 가하여 태풍에 동반되는 폭풍과 폭우로 인한 재산 및 인명 피해는 재해의 큰 부분을 차지하고 있다(최 기선 외, 2012).

한반도의 여름철 기상에 큰 영항을 주는 태풍은 기후변화와 더불어 고등학교 교과과정에서 중요하게 다뤄지고 있다. 과거 7차 교육과정에서는 우리나라에 영향을 준 태풍을 간단히 소개하고 태풍이 규모가 큰 기상현상이라는 것을 이해하도록 하였다. 개정 2009 교육과정은 이전과는 다르게 태풍을 더욱 강조 하여 태풍의 발생과 이동, 태풍의 위력과 해양과의 관계, 인간 생활과의 상호작용 등을 이해하도록 하였 다(교육인적자원부, 1997; 교육인적자원부, 2007).

7차와 개정 2009 교육과정의 고등학교 교과서에서 공통적으로 다루는 태풍에 관한 내용으로는 "태풍이 위도 $5 \sim 25^{\circ}$ 인 열대 해상에서 발생하며, 전향력이 없 는 적도에서는 생성되지 않는다(김희수 외, 2002; 이 문원 외, 2011; 정완호 외, 2011)"와 “태풍은 발생 초 기에는 서쪽이나 북서 방향으로 이동하고 중위도 지 역에서는 편서풍의 영향을 받아 포물선을 그리며 북 동 방향으로 이동한다(김희수 외, 2002; 이문원 외, 2011; 이태욱 외, 2011a, 2011b; 최변각 외, 2011a, 2011b)"가 있다.

학교 현장에서는 강의나 멀티미디어를 이용한 방법 으로 태풍을 소개한다. 대부분의 교과서에 삽입되어 있는 Fig. 1과 유사한 그림을 통해서 태풍의 발생에 는 전향력이 필요하고 발생한 뒤에는 얼마 동안 북 서방향으로 이동한다는 지식을 전달한다. 이 그림으 로 태풍과 전향력의 관계를 짐작하여 “태풍은 전향력 이 없는 적도에서는 생성되지 않는다."는 지식을 배 우는데 반해 이와 관련된 실험은 아직 개발되지 않 았다. 대기과학자들은 태풍의 발생과 진행 경로 등을 재현할 때 주로 수치모델을 이용하지만(윤순창과 이 갑복, 1990; 백종수와 백종진, 1999; 이조한 외, 1999; Liang and Chan, 2005; 한지영과 백종진, 2006; 김주 혜 외, 2007) 이를 학교 현장에 적용하기는 어렵다.

한편 실험수업은 자연에서 나타나는 현상을 통제 조절하여 가설을 검증하고 자연현상의 인과관계를 확 인할 수 있다(조희형과 최경희, 2005). 실험을 통하여 지식을 효과적으로 획득하고 학습한 내용을 오랫동안 파지할 수 있다. 이러한 관점에서 태풍에 관련된 실 험을 학교에서 수행한다면, 학생들에게 태풍에 대한 정확한 이해를 도울 수 있는 기회가 될 것이다.

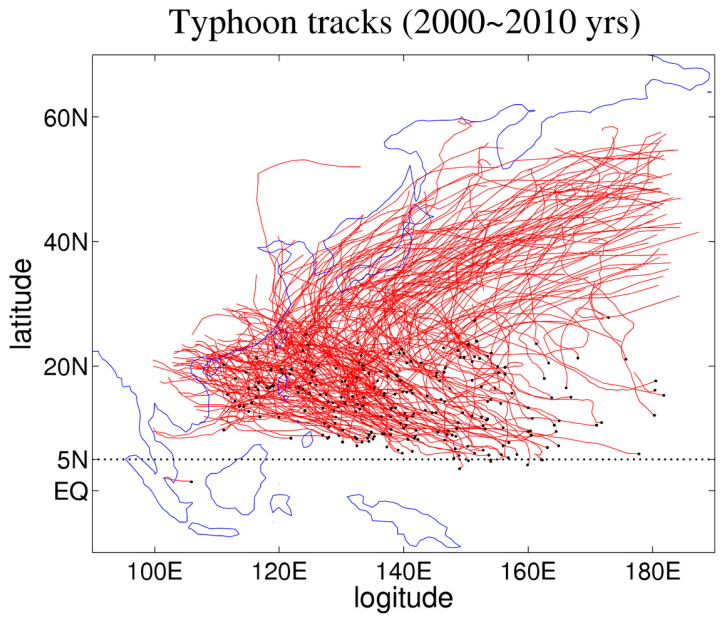

Fig. 1. Typhoon tracks for 11 years (2000 2010). Black dots are starting points of each typhoon. This figure shows that typhoons are likely to occur around $5 \sim 25^{\circ} \mathrm{N}$, then move northwestward, and some typhoons turn northeast.

Van Heijst(1994)는 회전원판을 활용한 실험 장비 를 개발하여, 지형적 베타효과를 이용한 다양한 소용 돌이의 움직임을 실험을 통하여 가시화하였다. 장승 환 외(2010)은 회전유체의 역학적 성질과 위치소용돌 이도 보존 법칙을 적용한 실험 장치를 개발하여 서 안 경계류를 재현하였으며, 경사진 바닥의 수조를 이 용하여 지형적 베타효과(topographical $\beta$-effect)에 의 해 생성된 서안 경계류를 이해하도록 하였다. 최근에 는 동일한 실험 장비를 활용하여 소용돌이의 움직임 에 대한 보다 큰 규모의 실험도 진행되었다(EUT, 2012).

이 연구는 장승환 외(2010)와 유사한 실험 장치로 경사진 바닥의 수조를 이용하여, 베타효과가 태풍의 이동에 영향을 줄 수 있음을 확인하였다. 이 논문에 서 제시한 실험 장치와 개발한 실험 방법을 통해 학 생들이 태풍의 생성과 유지에 대한 전향력의 역할과 태풍의 이동원리를 이해하는데 도움이 될 것으로 기 대한다.

\section{실험장치}

연구에서 개선한 실험 장치는 Fig. 2에 나타냈다. 실험 장치는 장승환 외(2010)와 $\mathrm{EUT}(2012)$ 의 실험 장치를 일부 개선하였다. 본 실험 장치의 큰 특징 중 하나는 수조에 소용돌이를 발생시키기 위한 작은 모 터를 이용한 것이다. 이 모터는 수조의 물을 국지적 


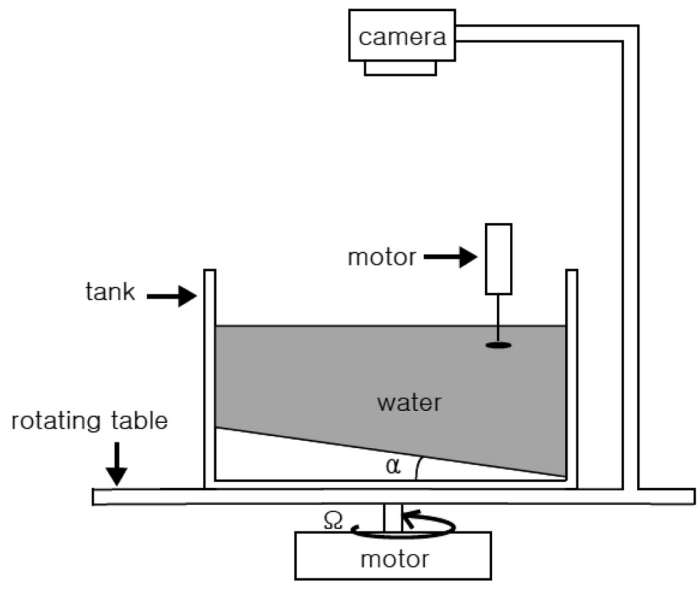

Fig. 2. Diagram of the experimental apparatus illustrating the section of a rectangular tank with a sloping bottom. Note that some experiments F0 and F1 were carried out with a flot-bottomed tank. The maximum depth of water and maximum height of bottom, and angular of slope are $17 \mathrm{~cm}, 11.5$ $\mathrm{cm}$ and $15^{\circ}$. For $\Omega$, see Table 1 .

으로 회전시켜 소용돌이를 만든다. 실험실에서 소용 돌이를 만드는 다른 방법은 Hopfinger and Van Heijst (1993)에 제시되어 있다. 회전 원판 위의 수조 는 직육면체 $(40 \mathrm{~cm} \times 40 \mathrm{~cm} \times 24 \mathrm{~cm})$ 로, 바닥이 경사진 것과 평평한 것 2 종류가 있다.

회전원판은 지구의 임의의 위도에 접하는 평면을 의미하므로(한국지구과학회, 1998; 장승환 외, 2011), 일정한 각속도를 갖는 반시계 방향으로 회전하는 수 조 속의 물은 북반구 중위도의 대기나 해양과 비슷 한 역학적 특징을 갖는다고 가정할 수 있다. 바닥이 경사진 경우, 물 두께의 변화에 의해 지형적 베타효 과가 나타나며, 물의 깊이가 얕아지는 방향이 실제 지구의 북쪽에 해당된다. 이는 수식 (1)로 설명이 가 능하다.

$$
\Pi=\frac{\varsigma+f}{H}
$$

위치소용돌이도 $(\Pi)$ 보존법칙에 따라 코리올리 변 수 $(f)$ 가 일정할 때, 유체의 높이(깊이) $H$ 가 변하면 상대소용돌이도 $(\zeta)$ 값의 변화가 나타난다. 베타효과 는 코리올리 변수 $(f)$ 의 남북방향 변화로 나타나는 현상이지만, 이 식에서는 상대소용돌이도 $(\zeta)$ 값과 유 체의 높이(깊이)의 변화로 이와 유사한 효과를 나타 낸다. 이를 지형적 베타효과라고 정의한다. 다시 말 하면, 평평한 바닥과는 달리 경사진 바닥을 사용하는 경우에는 수조에 방향성이 나타나므로 물의 깊이가 작아지는 방향이 북쪽을 가리킨다(장승환 외, 2010).

소용돌이를 발생시키는 회전 모터는 저기압성 모형 태풍을 나타내기 위하여 반시계방향으로 회전하도록 설계했고, 수면에서 $5 \mathrm{~cm}$ 깊이에 위치한다. 소용돌이 가 베타효과에 의해 이동하는 것을 관찰하기 위하여 회전 모터를 경사진 수조의 남동쪽에 설치하였다. 평 평한 바닥의 수조는 방향성이 없으나, 비교를 쉽게 하기 위해 카메라가 위치한 방향을 남쪽으로 설정하 였다. 논문에 제시된 사진은 $90 \mathrm{~cm}$ 높이에 설치된 디 지털 카메라로 촬영된 것이다.

\section{실험방법}

적도부근 $\left(0 \sim 5^{\circ}\right)$ 에서는 전향력이 존재하지 않기 때 문에 태풍이 발생되지 않는다(한국지구과학회, 1998). 즉 태풍이 생성되고 유지하는데 전향력은 매우 중요 한 요소이다.

Table 1은 이 연구에서 실시한 실험의 조건으로 2 가지 조건으로 실험을 수행하였다. 우선 전향력의 유 무와 태풍 발생의 연관성을 찾기 위해, 회전원판이 회전할 때와 회전하지 않는 환경에서 소용돌이를 발 생시켰다. 이들은 모두 평평한 바닥의 수조에서 수행 하였고 각각 $\mathrm{F} 0$ 과 $\mathrm{F} 1$ 으로 표현하였다. $\mathrm{F} 0$ 과 $\mathrm{F} 1$ 은 각 각 전향력이 작용할 때와 그렇지 않을 때의 환경을 의미한다(장승환 외, 2010). 따라서 이 두 실험 결과 를 통해 태풍의 발생과 유지에 전향력의 필요성을 확인할 수 있다.

Table 1. Experiment summary

\begin{tabular}{cccc}
\hline \hline Name & Bottom type of tank & Turn table rotation (count-clockwise) & Notes \\
\hline S0 & sloping & No & - \\
S1 & sloping & Yes $(\Omega=4)$ & beta effect (also Coriolis force) works \\
F0 & Flat & No & - \\
F1 & Flat & Yes $(\Omega=4)$ & constant Coriolis force only works \\
\hline
\end{tabular}

For all experiments, the water in tanks is forced by the anti-cyclonic (clockwise) rotating disk with the same angular velocity of $\omega=4 \mathrm{rpm}$ 

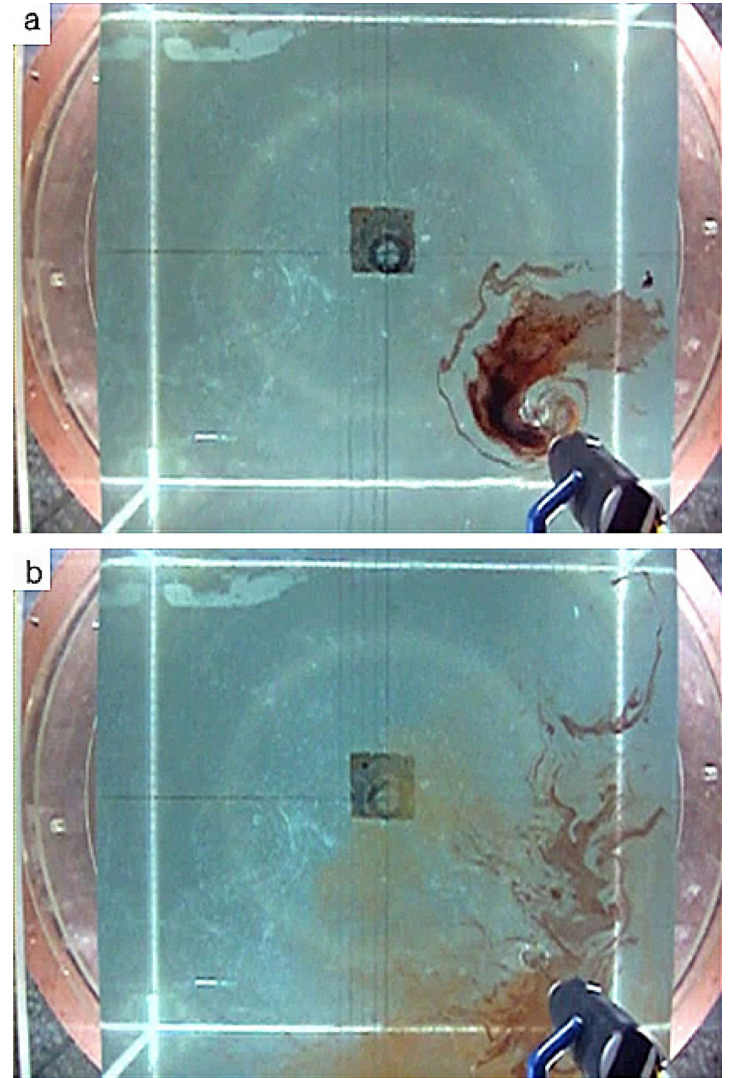

Fig. 3. Photographs of vortex revealed at the moment of dye injection in F0 (a), and at 5 seconds later (b).

다음으로 베타효과와 태풍의 이동 간의 연관성을 찾기 위해 평평한 바닥의 수조와 경사진 바닥의 수 조에서 실험을 수행하였다. 이들은 모두 회전원판이 회전하는 환경에서 수행하였고 각각 실험 $\mathrm{S} 1$ 과 F1으 로 표현하였다. 경사진 바닥을 이용할 때는, 장승환 외(2010)에서 제시된 것과 같이 회전유체의 두께 변 화로 위치소용돌이도를 보존하기 위한 지형적인 베타 효과가 나타난다(Holton, 2004; Pedlosky, 1987). 행 성 소용돌이도의 남북 경도로 나타나는 베타효과는 저위도지방에서 생성된 태풍의 이동에 큰 영향을 준 다(Rossby and Collaborators, 1939; Adem, 1956; Chan and Williams, 1987). 이들의 연구에 의하면, 태풍을 이동시키는 중요한 요소 중 하나인 바람이 없을 때에도, 태풍 자체의 소용돌이도(vorticity)와 절 대 소용돌이도(absolute vorticity)의 상호작용에 의해 태풍이 북서쪽으로 움직인다. S1과 F1의 실험을 통 해 전향력이 태풍의 이동에도 큰 영향을 주는 것을 확인할 수 있다. 회전 각속도는 두 조건에서 동일하
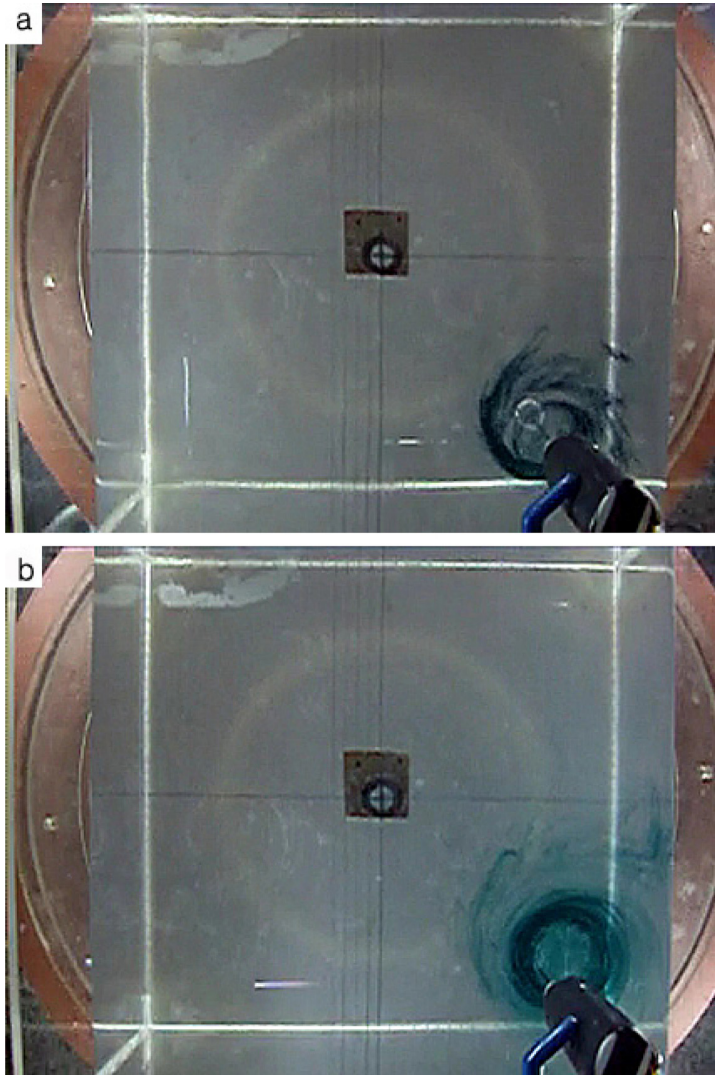

Fig. 4. Same as Fig. 3 except for experiment F1. Vortex is almost stay and maintains stable for a few minutes.

게 $4 \mathrm{rpm}$ 으로 설정하였다.

모든 실험은 15 분 동안 실험 조건에서 그대로 두 어 수조 내부의 물이 안정화된 후 소용돌이를 생성 하는 발생기를 5 초간 작동하였다. 소용돌이의 이동과 유지시간을 시각적으로 확인하기 위해 소용돌이가 생 성되면 바로 염료를 떨어뜨리고 관찰하였다.

\section{실험결과}

Fig. 3 은 $\mathrm{F} 0$ 의 실험에서 촬영된 사진이다. 먼저 Fig. 3a는 회전하지 않는 수조에서 소용돌이를 발생 시킨 직후, 즉 회전모터를 정지한 직후에 염료를 투 여한 사진이다. 갈색 염료가 물 표면에서 반시계 방 향으로 회전하는 소용돌이 모양으로 분표한다. 이는 회전모터가 국지적으로 물을 반시계 방향으로 회전시 켜 소용돌이가 만들어지는 것을 보여준다. 그런데 이 후 5 초가 지난 후에는 Fig. $3 \mathrm{~b}$ 에서 볼 수 있듯이 염 료가 특별한 모양 없이 흩어졌다. 이 결과로 비회전 계의 유체에서는 소용돌이가 유지되지 않음을 제시한 


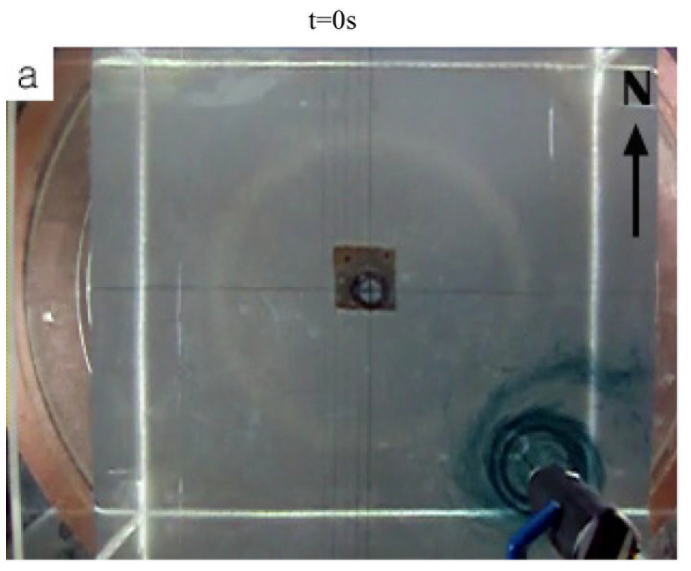

$t=6 \mathrm{~s}$

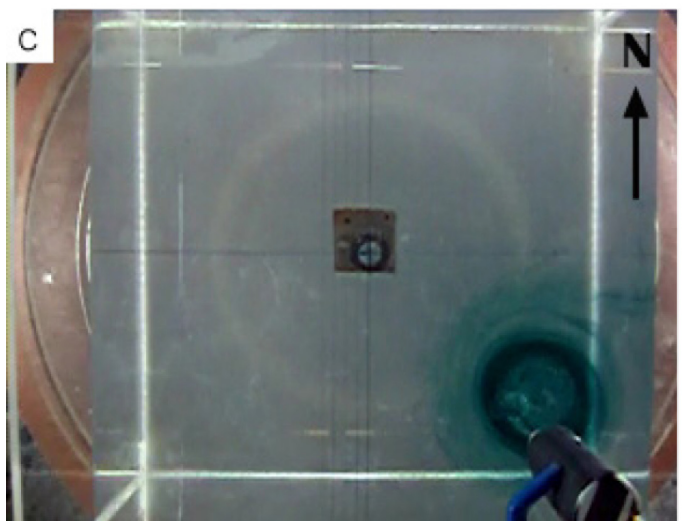

$\mathrm{t}=3 \mathrm{~s}$

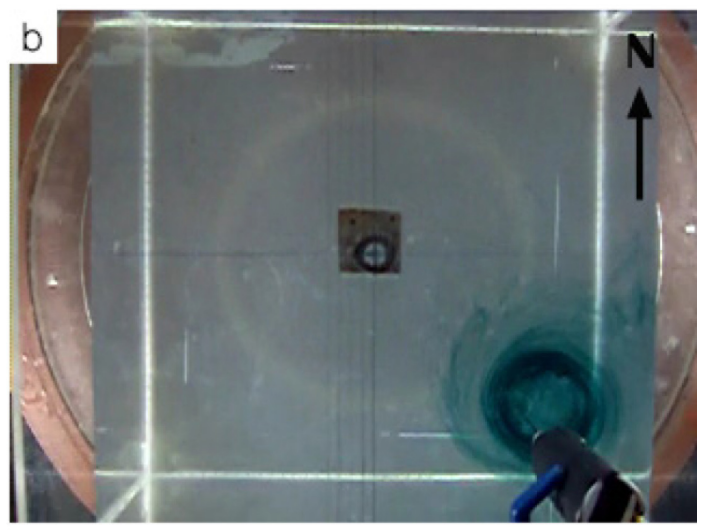

$t=9 \mathrm{~s}$

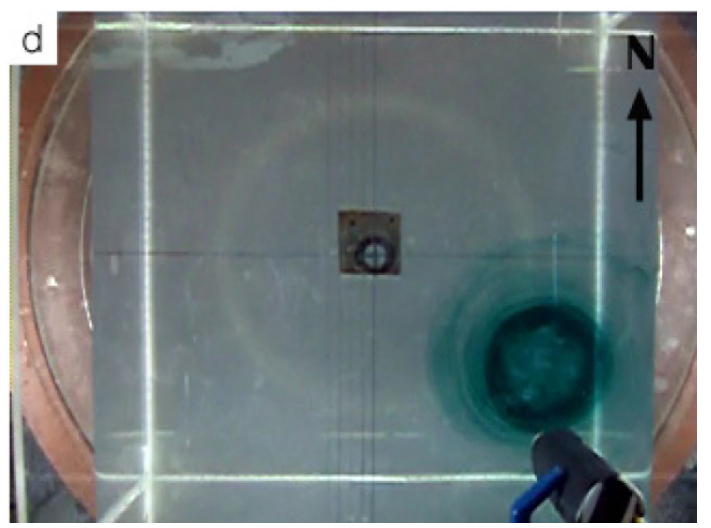

Fig. 5. Vortex from the experiment F1 for the first $0 \sim 9$ seconds after dye injection. It locates the same place in the tank. The North mark is given for comparison with vortex in sloping tank.

다. 전향력을 표현하기 위해서 회전 원판을 사용하는 것을 고려하면(최진호, 2004; 김은주 외, 2009; 장승 환 외, 2010; 장승환 외, 2011), Fig. 3b의 결과로 태 풍과 같은 소용돌이는 전향력이 작용하지 않으면 생 성 · 유지되지 않음을 확인할 수 있다. 이는 태풍으로 성장하기 위해서는 반드시 전향력이 작용해야만 한다 는 것을 보여준다(한국기상학회, 2003).

Fig. 4는 Fig. 3과 같은 방법으로 촬영한 실험 $\mathrm{F} 1$ 의 결과이다. $\mathrm{F} 1$ 은 $\mathrm{F} 0$ 와는 달리 소용돌이가 생성된 후 3 분 이상 그 형태를 유지한다. 또한 시간이 지나 도 소용돌이는 생성된 위치에서 움직이지 않음을 Fig. 5 를 통해 확인할 수 있다. F0과 F1의 실험을 학 교에서 실시한다면 태풍의 생성에는 전향력이 필요하 며 적도부근에서는 태풍이 발생하기 어렵다는 것을 쉽게 이해할 수 있을 것이다.

앞에서 언급했듯 F1의 소용돌이는 생성되었지만 생성된 장소에 그대로 머물러 있었다. 전향력의 변화
와 태풍의 움직임과 연관성을 확인하기 위한 실험 $\mathrm{S} 1$ 을 실시하였다. 수조의 바닥 모양을 제외하고는 F1 과 S1의 실험 조건은 동일하다. 장승환 외(2010)는 경사진 바닥의 수조에 담긴 물은 마치 행성 소용돌 이도의 남북 경도로 나타나는 베타효과와 유사한 역 학적 성질을 갖게 되지만 이때의 베타효과는 물의 두께 변화로 유발된 것이다(Holton, 2004; Pedlosky, 1987).

Fig. 6은 S1의 실험결과를 3초 간격으로 촬영한 것 이다. 수조 속의 소용돌이는 시간이 지나면서 북서방 향으로 이동한다. 이 결과는 태풍을 이동시키는 주요 요소 중 하나인 바람이 존재하지 않더라도, 자체의 소용돌이와 베타효과에 의해 북서쪽으로 이동한다는 것을 확인할 수 있다. 그리고 Fig. 6에서 소용돌이 이동 모습은 다른 연구자의 실험(Carnevale et al., 1991)과 위치소용돌이도 보존법칙과 베타효과를 고려 한 수치모델 연구(Orlandi, 2000; Carnevale et al., 
$\mathrm{t}=0 \mathrm{~s}$

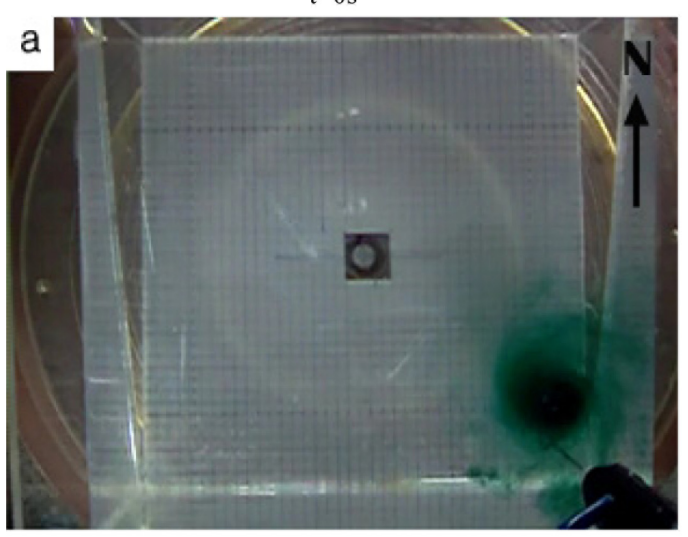

$t=6 s$

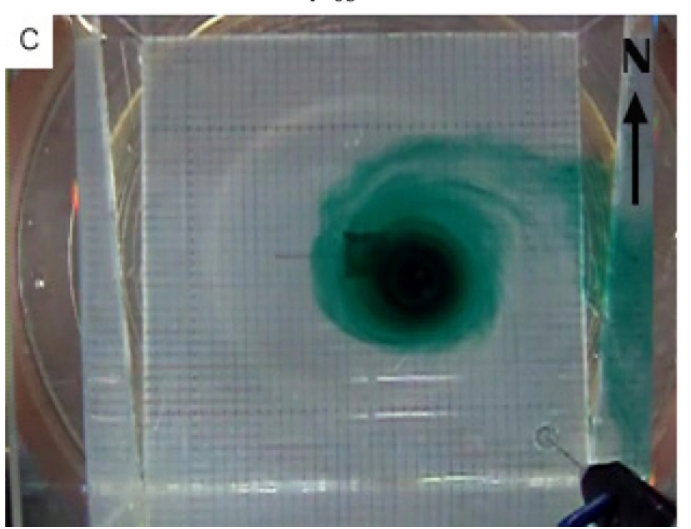

$\mathrm{t}=3 \mathrm{~s}$

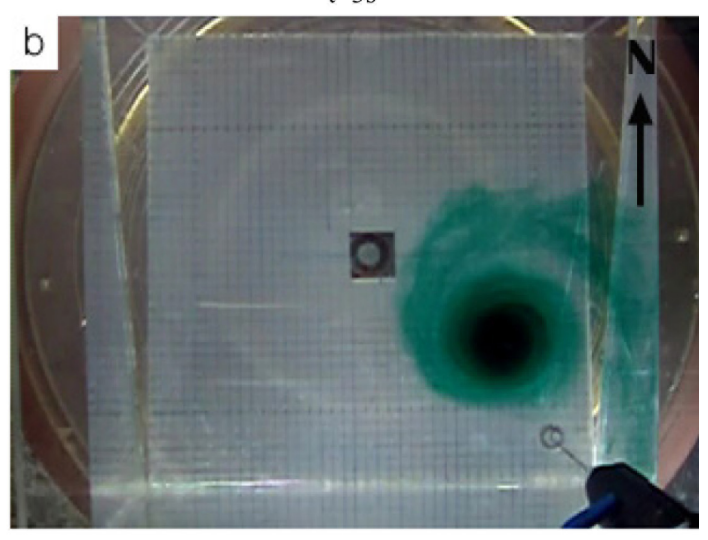

$t=9 \mathrm{~s}$

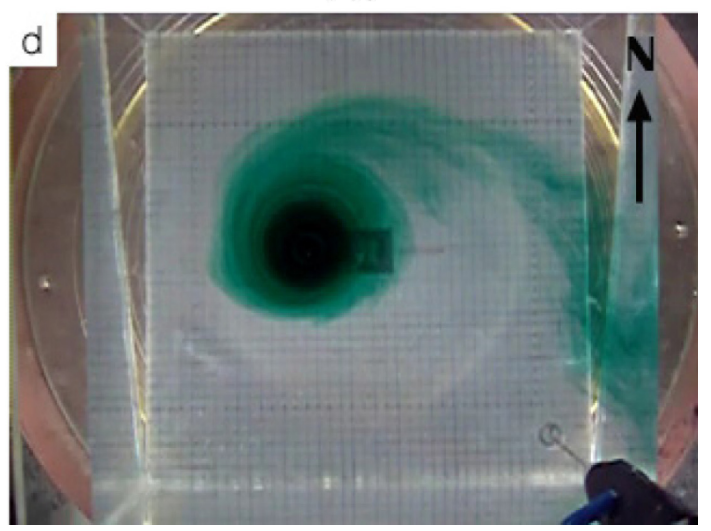

Fig. 6. Same as in Fig. 5 except for experiment S1. The arrow points to the down gradient of depth.

1997)의 결과와 매우 유사한 형태를 보인다.

태풍은 강한 바람과 많은 강수를 동반하기 때문에 그 진로를 정확히 예측하는 것은 매우 중요하다. Fig. 1에 나타난 태풍의 움직임이 배경 바람뿐 아니 라 다른 역학과정(즉, 베타효과)에서도 영향을 받는다 는 것을 실험을 통해 이해할 수 있을 것이다. 베타효 과와 태풍의 움직임에 대해서는 Rossby(1948)가 최 초로 제시한 이후에 많은 연구가 있었다. 이후 Chan and Williams(1987)과 Fiorino and Elsberry(1989)은 태풍 소용돌이와 행성 소용돌이도의 비선형적 상호작 용에 의한 태풍의 이동 메커니즘을 명확히 밝혔다.

\section{결론 및 토의}

우리는 학교 현장에서 학생들에게 태풍의 발생과 발달, 이동을 수업할 때 유용하게 쓰일 수 있는 실험 장치를 개선하고 방법을 개발하였다. 학생들은 몇몇 실험을 수행하면서 태풍의 발생에 전향력이 필수적인
요소인 것과 태풍의 움직임에 미치는 전향력의 역할 등을 이해할 수 있을 것이다. 실험 장치는 전향력을 나타내기 위한 회전원판, 지형적 베타 효과를 나타내 기 위한 경사진 바닥의 수조와 단순히 전향력만을 보기 위한 평평한 바닥의 수조, 그리고 태풍과 유사 한 형태로 회전하는 소용돌이를 생성하기 위한 발생 기로 이뤼져 있다.

회전원판이 회전할 때와 그렇지 않을 때의 수조 속의 물은 각각 전향력이 작용하는 환경과 작용하지 않는 환경을 의미한다. 이 두 환경에 놓인 평평한 바 닥의 수조 속에서 만든 소용돌이의 모습을 관찰하였 다. 전향력이 작용한 환경의 수조(실험 F1)에서는 소 용돌이가 안정적으로 유지되었다. 반면에 전향력이 없는 경우(실험 $\mathrm{F} 0$ )는 발생기에 의해 생성된 소용돌 이는 이내 소멸되고 말았다. 이를 통해 전향력은 태 풍이 생성되고 유지되기 위해 필수적인 요소임을 알 았으며, 적도에서 태풍이 생성되지 않는 현상을 이해 할 수 있다. 이 두 실험을 통해 학생들은 Fig. 1에 
나타난 적도 부근에서 태풍이 발생하기 어렵다는 현 상을 좀 더 쉽게 이해할 수 있을 것이다.

우리는 또한 태풍의 움직임과 전향력과의 관련성을 이해할 수 있는 실험을 수행하였다. 이 실험은 F1실 험과는 다르게 수조 바닥에 경사를 주어 베타 효과 가 작용하는 환경을 구현하였다. 평면 바닥의 수조를 이용한 앞의 F1 실험에서는 소용돌이가 생성된 후 거의 움직임 없이 최초 생성된 곳에 정체되어 있었 다. 반면에 실험 $\mathrm{S} 1$ 에서 수조 속의 소용돌이는 생성 된 후 북서방향으로 이동하였다(실험 $\mathrm{S} 1$ ). 이것은 경 사 바닥으로 인한 베타효과가 소용돌이를 북서쪽으로 이동시킨다는 것을 나타낸다. 따라서 여기 두 실험을 이용하면 북반구에서 생성되는 태풍의 발생 초기에 북서방향으로 이동하는데 베타효과의 영향이 크다는 것을 의미한다.

태풍은 우리의 일상생활에 많은 영향을 주기 때문 에 중·고등학교 교육과정에서 중요하게 다뤄지고 있 다. 이 연구에서 개선한 실험 장치와 방법을 통해 학 교 현장에서 학생들이 태풍의 생성과 발달에 전향력 이 매우 중요한 요소로 작용하며, 태풍 이동에도 전 향력이 작용한다는 것을 이해하는데 도움을 줄 수 있을 것으로 생각한다. 이 연구에서 개선한 실험 장 치를 이용하여 학생들은 여러 새로운 실험을 설계할 수 있을 것이다. 예를 들면, 실험 $\mathrm{S} 1$ 에서는 원판의 회전 속도를 $4 \mathrm{rpm}$ 으로 설정하였는데, "만약 회전원 판의 속도를 증가시키면 어떤 변화가 있을까?" 혹은 “바닥이 다른 모양일 때 소용돌이는 어떻게 변할까?" 와 같은 창의적인 문제들을 학생들 스스로 만들 것 으로 기대한다(Appendix 1).

\section{감사의 글}

논문에 귀중한 조언을 주신 소선섭 교수님과 익명 의 심사위원께 감사드립니다. 이 연구는 기상청 기후 기술개발사업(CATER 2012-3053)의 지원으로 수행되 었습니다.

\section{참고문헌}

교육인적자원부, 1997 , 과학과 교육과정. 서울, 90 p. 교육인적자원부, 2007 , 과학과 교육과정. 서울, 83 p. 김은주, 이상법, 윤일희, 이효녕, 2009 , 전향력에 의한 현상 을 효과적으로 교육시킬 수 있는 실험 장치의 개발. 한 국지구과학회지, $30,787-798$.
김주혜, 추교명, 김백조, 원성희, 권혁조, 2007 , 이동격자태 풍모델을 이용한 2006년 태풍의 진로 및 강도 예측성능 평가. 한국기상학회 대기지, 17, 207-216.

김희수, 정남식, 신동원, 박정웅, 이정식, 한홍렬, 박용선, 2002, 지구과학I. 천재교육, 서울, 247 p.

백종수, 백종진, 1999, 초기 소용돌이 구조, 대칭 및 비대 칭 순환, 그리고 순압 태풍 운동. Asia-Pacific Journal of Atmospheric Sciences, 35, 201-214.

윤순창, 이갑복, 1990 , 순압 대기에서의 태풍의 이동 성향 에 관한 연구. Asia-Pacific Journal of Atmospheric Sciences, 26, 25-37.

이문원, 전성용, 권석민, 진만식, 신석주, 임부철, 2011 , 지 구과학I. 금성출판사, 서울, 283.

이조한, 이동규, 전종갑, 1999 , 초기화된 태풍의 구조 및 발달의 연구. Asia-Pacific Journal of Atmospheric Sciences, 35, 405-420.

이태욱, 박수인, 김완섭, 강석철, 이용준, 이혜경, 장헌영, 김병노, $2011 \mathrm{a}$, 지구과학I. 교학사, 서울, 303 p.

이태욱, 박수인, 김완섭, 강석철, 이용준, 이혜경, 장헌영, 김병노, $2011 \mathrm{~b}$, 지구과학II. 교학사, 서울, 303 p.

장승환, 박효진, 조규성, 문병권, 2011, 전향력 발생 원리를 고등학생들에게 설명하기 위한 새로운 방법. 한국지구 과학회지, 32, 73-83.

장승환, 신정선, 문병권, 2010, 서안경계류 역학을 이해하기 위한 실험 장치 및 방법 개발. 한국지구과학회지, 31 , 88-94.

정완호, 김웅태, 신미영, 고현덕, 권혁빈, 김낙현, 김희동, 박종석, 임태훈, 송현미, 윤용, 김영준, 2011, 과학. 교학 사, 서울, $443 \mathrm{p}$.

조희형, 최경희, 2005 , 과학교육의 이론과 실제. 교육과학사, 서울, $669 \mathrm{p}$.

최기선, 김태룡, 2011, 한반도에 영향을 주는 태풍의 접근 진단 지수 개발. 한국지구과학회지, 32, 347-359.

최기선, 차유미, 김태룡, 2012, 한반도에 상륙한 태풍 빈도 수의 십년간 변동 특성. 한국지구과학회지, 33, 49-58.

최변각, 이해신, 추병수, 문병권, 소영무, 이지은, 이정은, 조명아, 2011a, 지구과학I. 천재교육, 서울, 319 p.

최변각, 이해신, 추병수, 문병권, 소영무, 이지은, 이정은, 조명아, 2011b, 지구과학II. 천재교육, 서울, $351 \mathrm{p}$.

최진호, 2004, 회전 원반을 이용한 전향력 실험 방법 개선. 한국교원대학교 교육학석사학위논문, 108 p.

한국기상학회, 2003, 대기과학개론. 시그마프레스, 서울, $405 \mathrm{p}$.

한국지구과학회, 1998, 지구과학개론. 교학연구사, 서울, $818 \mathrm{p}$.

한지영, 백종진, 2006, 대기 대순환 모형과 해수면 온도 관 측 자료를 이용한 태풍 활동의 계절 예측 가능성. 한국 지구과학회지, 27, 653-658.

Adem, J., 1956, A series solution for the barotropic vorticity equation and its application in the study of atmospheric vortices. Tellus, 3, 364-372.

Carnevale, G.F., Briscolini, M., Kloosterziel, R.C., and Vallis, G.K., 1997, Three dimensionally perturbed vortex 
tubes in an rotating flow. Journal of Fluid Mechanics, 341, 127-163.

Carnevale, G.F., McWilliams, J.C., Pomeau, Y., Weiss, J.B., and Young, W.R., 1991, Evolution of vortex statistics in two-dimensional turbulence. Physical Review Letters, 66, 2735-2737.

Cha, E.J., Masahide, K., Lee, E.J., Jhun, J.G., 2007, The recent increase in the heavy rainfall events in august over the Korean Peninsula. Journal of the Korean Earth Science Society, 28, 585-597.

Chan, J.C.L. and Williams, R.T., 1987, Analytical and numerical studies of the Beta-Effect in tropical cyclone motion, part I: Zero mean flow. Journal of the Atmospheric Sciences, 44, 1257-1265.

Eindhoven University of Technologye, 2012, http://web.phys. tue.nl/nl/de_faculteit/capaciteitsgroepen/transportfysica/ fluid_dynamics_lab/research/vortex_dynamics/topogr/ (검색일: 2012. 9. 8.)

Fiorino, M. and Elsberry, R.L., 1989, Contribution to tropical cyclone motion by small, medium and large scales in the initial vortex. Monthly Weather Review, 117, 721-727.

Holton, J.R., 2004, An introduction to dynamic meteorology. Elsevier Academic Press, CA, USA, 535 p.
Hopfinger, E.J. and Van Heijst, G.J.F., 1993, Vortices in rotating fluids. Annual Review of Fluid Mechanics, 25, 241-289.

Liang, X. and Chan, J.C.L., 2005, The effects of the full Coriolis Force on the structure and motion of a tropical cyclone, part I: Effects due to vertical motion. Journal of the Atmospheric Sciences, 62, 3825-3830.

Orlandi, P., 2000, Fluid flow phenomena: A numerical toolkit (fluid mechanics and Its applications). Kluwer Academic Publisher, Dordrechi, Netherlands, 356 p.

Pedlosky, J., 1987, Geophysical fluid dynamics. SpringerVerlag, NY, USA, $710 \mathrm{p}$.

Rossby, C.G., 1948, On displacements and intensity changes of atmospheric vortices. Journal of Marine Research, 7, 175-187.

Rossby, C.G. and Collaborators, 1939, Relation between variations in the intensity of the zonal circulation of the atmosphere and the displacements of the semipermanent centers of action. Journal of Marine Research, 38-55.

Van Heijst, G.J.F., 1994, Topography effects on vortices in a rotating fluid. An International Journal of Theoretical and Applied Mechanics, 29, 431-451. 
552

위지은 · 장승환 · 문병권

Appendix 1. Experiment report

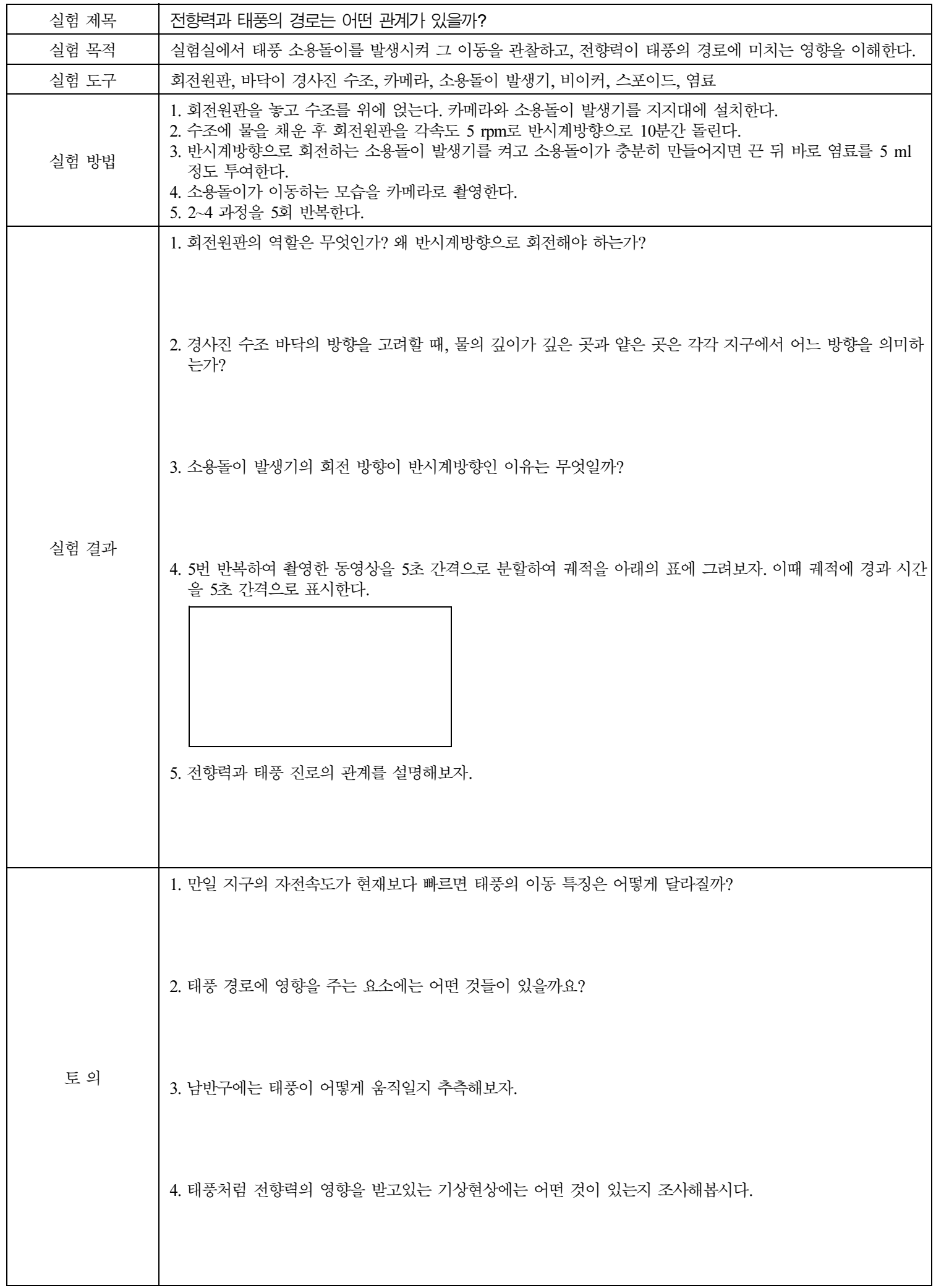




\section{<예시답안>}

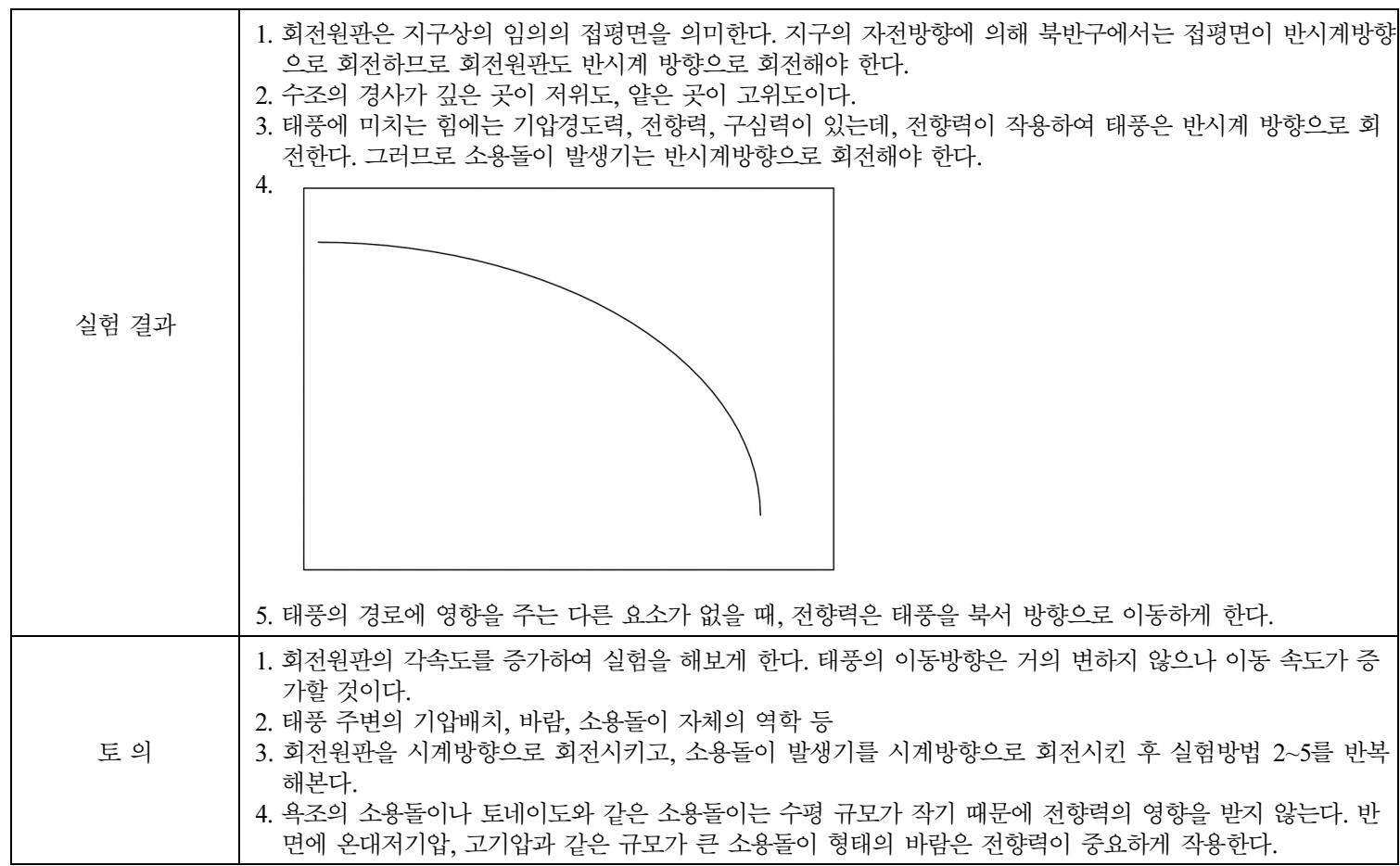

